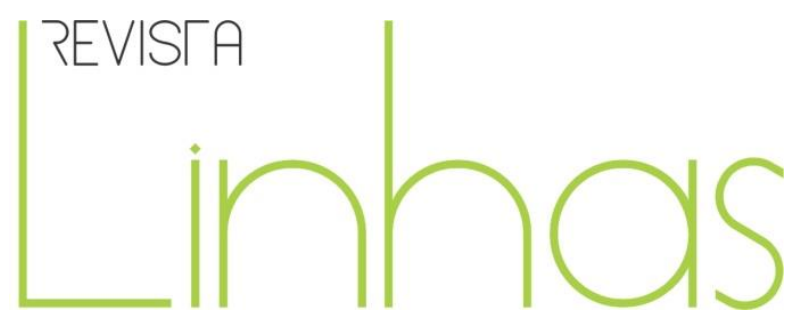

\title{
O que são centros de documentação? O caso do Centro de Documentação do Centro de Estudos e Investigações em História da Educação
}

\begin{abstract}
Resumo
Este artigo faz uma reflexão teórica acerca de quatro tipos de instituições de memória: arquivos, bibliotecas, museus e centros de documentação, trazendo suas similaridades e suas diferenças, buscando entender o que diferencia o último das demais. Para isso, utiliza autores como Bellotto (2000) e Tessitore (2003). O artigo aborda, ainda, a constituição do Centro de Documentação do Centro de Estudos e Investigações em História da Educação - CEDOC-CEIHE vinculado à Faculdade de Educação da Universidade Federal de Pelotas (RS), com importante atuação na preservação de patrimônio documental referente à História da Educação em Pelotas e região circunvizinha. Dessa forma, o presente trabalho estrutura-se da seguinte maneira: primeiramente uma discussão teórica acerca dos quatro tipos de instituições de memória e, na sequência, aborda-se o CEDOC-CEIHE, relacionando com a teoria explicitada no tópico anterior e por fim, alguns aspectos conclusivos da pesquisa.
\end{abstract}

Palavras-chave: Instituições de Memória. Arquivos. Centro de Documentação.

\author{
Renata Brião de Castro \\ Universidade Federal de Pelotas \\ - UFPel - Brasil \\ renatab.castro@gmail.com \\ Carla Rodrigues Gastaud \\ Universidade Federal de Pelotas \\ - UFPel - Brasil \\ crgastaud@gmail.com
}

\section{Para citar este artigo:}

CASTRO, Renata Brião de; GASTAUD, Carla Rodrigues. O que são centros de documentação? O caso do Centro de Documentação do Centro de Estudos e Investigações em História da Educação. Revista Linhas. Florianópolis, v. 18, n. 37, p. 263-282, maio/ago. 2017. 


\title{
What are documentation centers? The case of the Documentation Center of the Center for Studies and Research in Education History
}

\begin{abstract}
This article is a theoretical reflection about four types of memory institutions: archives, libraries, museums and documentation centers; discussing their similarities and their differences, we seek to understand what distinguishes the latter from the others and, with this purpose, we refer to authors like Bellotto (2000) and Tessitore (2003). The article also approaches the establishment of the Documentation Center of the Center for Studies and Research in Education History - CEDOC-CEIHE - linked to the College of Education of the Federal University of Pelotas (RS), with an important role in the preservation of documentary heritage related to the History of Education in Pelotas and surrounding region. Thus, this paper is structured as follows: first a theoretical discussion about the four types of memory institutions; thereafter it addresses the CEDOC-CEIHE, relating it to the theory explained in the previous topic; and finally, some conclusive aspects of the research.
\end{abstract}

Keywords: Memory Institutions. Collections. Documentation Centre. 


\section{Introdução}

Instituições de memória - arquivos, museus, bibliotecas e centros de documentação - salvaguardam variadas tipologias de acervo, e apresentam tanto semelhanças quanto diferenças entre si. As afinidades entre estas instituições são marcantes, a iniciar por trabalharem com patrimônio e serem instituições de salvaguarda de acervos.

Conforme Chagas, "museus, centros de documentação, bibliotecas e arquivos são instituições culturais e de memória, operando com patrimônios e documentos, e atravessadas de ponta a ponta por linhas de poder, formando uma espécie de grande teia" (CHAGAS, 2002, p. 25).

Neste artigo, objetivamos refletir acerca destas instituições de memória buscando suas similaridades e suas diferenças. Outrossim, o trabalho aborda a implantação do Centro de Documentação do Centro de Estudos e Investigações em História da Educação - CEDOC-CEIHE - vinculado à Faculdade de Educação da Universidade Federal de Pelotas (RS), compreendendo esse espaço como uma importante instituição de memória para acervos e pesquisas no âmbito da História da Educação. Ressalta-se a necessidade de diferenciar essas instituições de memória, para compreensão do que é um centro de documentação, bem como para pensar sobre o CEDOC-CEIHE.

O Centro de Estudos e Investigações em História da Educação foi criado no ano de 2000, para reunir e formar pesquisadores que investigam temas relativos à História da Educação (ARRIADA; TAMBARA; TEIXEIRA, 2012). Internamente, o CEIHE se ramifica em duas frentes de trabalho: o Centro de Pesquisa e o Centro de Documentação (TAMBARA, 2005), sendo este último o objeto deste artigo.

Este trabalho inicia pela diferenciação entre arquivos, museus, bibliotecas e centros de documentação. A partir desta teorização, aborda-se o CEDOC-CEIHE trazendo sua constituição, sua trajetória e seu acervo. Para isso, utilizamos entrevistas realizadas com os gestores do Centro de Documentação a fim de entender a estrutura e funcionamento local. 


\section{Sobre arquivos, museus, bibliotecas e centros de documentação:}

\section{convergências e divergências}

O patrimônio pode estar representado por monumentos, prédios e casas históricas, objetos tridimensionais, obras de arte, saberes, costumes, modos de fazer, lugares. Para Horta, o patrimônio cultural "se manifesta como um conjunto de bens e valores, tangíveis e intangíveis, expressos em palavras, objetos, monumentos e sítios, ritos ou celebrações, hábitos e atitudes" (HORTA, 2000, p.29).

Também são patrimônio os documentos que estão sob a proteção de arquivos e centros de documentação, os quais abrigam em seus acervos diversos documentos ligados a variados assuntos e tipologias.

Fratini escreve que:

[...] é cada vez maior a preocupação com a conservação e a preservação do patrimônio histórico e cultural de uma sociedade, de um país. As dimensões e as características que definem o nosso tempo e espaço geram discussões constantes sobre o que, como e para quem preservar. (FRATINI, 2009, p. 1)

Quer tomemos patrimônio como Mário Chagas o define: "conjunto de bens culturais sobre o qual incide uma determinada carga valorativa" (1996, p. 45), ou o entendamos com Maria de Lourdes Horta como "bens e valores materiais e imateriais, transmitidos de geração a geração na trajetória de uma comunidade" (2000, p. 29), documentos são patrimônio.

Assim, no que toca ao patrimônio, documento pode ser compreendido em dois sentidos: um mais abrangente, que define como documento qualquer objeto, seja ele bidimensional ou tridimensional, desde que esteja imbuído de um significado e de que seja lançado sobre esse objeto um olhar interpretativo e investigativo; e outro mais fechado, que toma documento apenas como escrita no suporte papel, "[...] no sentido restrito o documento é o livro, folheto, revista, relatório, entre outros exemplos. [...] No sentido amplo o documento pode ser visto como bem cultural, ou seja, um monumento, um sítio paisagístico" (TANUS; RENAU, ARAÚJO, 2012, p. 6). Na Museologia, o 
documento é tratado no seu sentido mais geral, ou seja, os objetos que estão nos acervos das instituições museológicas são documentos, estejam eles em suporte papel ou não.

Dentro dessa conjuntura, arquivos, bibliotecas, museus e centros de documentação têm em comum o fato de salvaguardarem documentos que são patrimônio e, consequentemente, uma memória relativa a eles. Além disso, essas instituições compartilham a possibilidade de desenvolver atividades semelhantes com o seu acervo. Esses quatro tipos de instituições de memória possuem em comum o fato de terem sob guarda acervos e documentos referentes à função de cada instituição. Apesar das convergências, esses locais também apresentam diferenças no que tange a função e organização de acervos e documentos. Assim sendo, a seguir elencaremos algumas características desses quatro tipos de instituições de memória.

Viviane Tessitore se refere a museus, bibliotecas, arquivos e centros de documentação como “entidades de preservação documental” (TESSITORE, 2003, p. 11) e compreende documento em seu sentido mais abrangente.

Os arquivos acumulam documentos de uma única fonte geradora. No caso dos arquivos públicos, os documentos possuem uma finalidade administrativa, jurídica ou social e a referência é feita por conjuntos de documentos e não objeto por objeto como é o caso dos museus e das bibliotecas (TESSITORE, 2003). Os arquivos se constituem de fundos documentais que se referem ao produtor dos documentos no exercício de suas atividades, ou seja, são acumulados de forma orgânica o que difere das bibliotecas e museus que acumulam coleções de forma artificial em decorrência de suas finalidades.

As bibliotecas, por sua vez, constituem um acervo reunido de forma artificial e, de acordo com Tessitore, são um órgão colecionador e não um órgão receptor como os arquivos públicos. Sendo um órgão colecionador, as bibliotecas definem o teor de seu acervo. (TESSITORE, 2003).

Os museus, ainda segundo Tessitore, possuem "objetos tridimensionais, originados da atividade humana ou da natureza, reunidos, artificialmente, sob a forma de coleções, em torno de seu conteúdo ou função". A organização dos museus é pautada pela natureza e finalidade de seu material (acervo), possuindo finalidades educativas, 
científicas e culturais e fazendo referência a cada objeto de seu acervo (TESSITORE, 2003, p. 13).

Por último, a autora apresenta os centros de documentação como uma "entidade híbrida", vinculando aspectos das outras três instituições listadas anteriormente. De acordo com a autora, justamente por seu caráter híbrido, os centros de documentação não contam com uma teoria metodológica específica para o tratamento de seu acervo (TESSITORE, 2003, p. 13), o qual pode ser constituído por material bibliográfico, arquivístico ou museológico. Centros de documentação são órgãos colecionadores e fazem referência a uma área específica, ou seja, é uma característica desses locais a especialização em uma área de conhecimento e a partir disso a reunião de seu acervo e a definição de suas funções de pesquisa, bem como a composição de sua equipe técnica científica (TESSITORE, 2003 pp. 14,15).

O gerenciamento de um acervo e seu tratamento técnico depende das particularidades do mesmo: documentos de arquivos serão tratados seguindo os preceitos da Arquivologia, da mesma forma que objetos museológicos seguirão as diretrizes museológicas.

Um mesmo centro de documentação pode apresentar acervos de Arquivologia, Biblioteconomia e Museologia, pois esses espaços têm como uma de suas características o fato de abrangerem tipologias de acervo diversificadas referentes à mesma temática.

No caso do Centro de Documentação do Centro de Estudos e Investigações em História da Educação, estudado neste trabalho, há uma predominância de acervos da área da Biblioteconomia. De todo o acervo salvaguardado pelo CEDOC-CEIHE, a maioria é de livros organizados de acordo com os preceitos biblioteconômicos. 
Figura 1 - Livros do acervo do CEDOC, organizados no local.
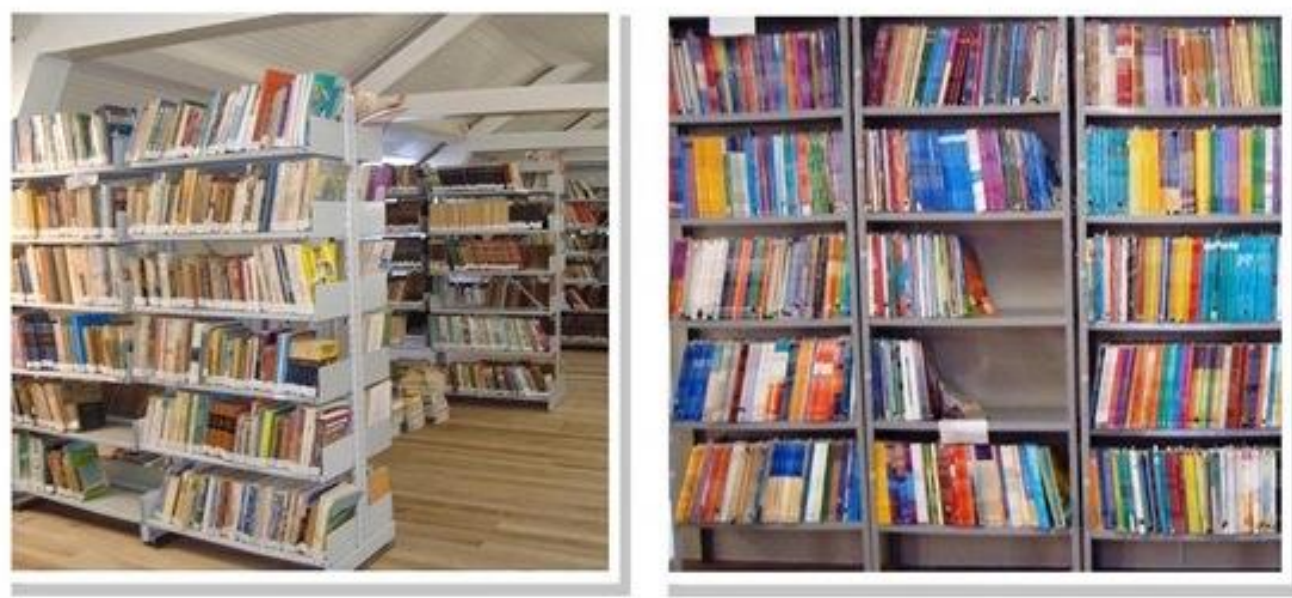

Fonte: foto da autora, 2014.

Neves pontua como peculiaridade desses espaços o fato de serem especializados em determinados assuntos:

Uma característica marcante dos centros de documentação está na sua configuração, ou seja, esses espaços normalmente estão atrelados ao desenvolvimento de trabalhos ligados à área de informação especializada, como o trabalho de organização de arquivos, coleções de revistas, fotografias, jornais e bibliotecas. Esses locais são considerados geradores e produtores de informação, um diferencial para seu funcionamento, porque se tornam imprescindíveis ao desenvolvimento de pesquisas. (NEVES, 2005 p. 15)

No Centro de Documentação - CEDOC-CEIHE -, percebem-se claramente essas características: há acervos das três tipologias - Museologia, Biblioteconomia e Arquivologia -, e todo esse material está alinhado a uma temática central que é a História da Educação.

Heloísa Bellotto também escreve sobres estes quatro tipos de instituições, as quais ela se refere como "instituições armazenadoras/referenciadoras de documentos" (2000, p. 156). Conforme Bellotto, os documentos de arquivos são resultantes de funções administrativas e funcionais de diferentes órgãos e/ou pessoas, chegando até os arquivos de forma natural, não formando coleções e, sim, fundos (BELLOTTO, 2000). O termo 
“fundo" é usado para designar o "acervo arquivístico produzido, recebido e acumulado em processo natural por uma mesma instituição, entidade ou pessoa; conjunto de documentos de uma mesma proveniência" (GLOSSÁRIO ARQUIVÍSTICO, 2014).

A Lei de Arquivos $n^{\circ} 8.159$, em seu parágrafo $2^{\circ}$ diz que:

Consideram-se arquivos para os efeitos dessa lei, os conjuntos de documentos produzidos e recebidos por órgãos públicos, instituições de caráter público e entidades privadas, em decorrência do exercício de atividades específicas, bem como por pessoa física, qualquer que seja o suporte da informação ou a natureza dos documentos. (BRASIL, 1991)

Já os documentos que chegam às bibliotecas são resultantes de acumulação seletiva, ou seja, estes materiais não são reunidos de maneira espontânea, como é o caso dos arquivos, mas sim selecionados para fazer parte do acervo de uma determinada biblioteca, formando, por esse motivo, o que chamamos de "coleções". O acervo biblioteconômico é composto majoritariamente por livros, mas também conta com publicações periódicas, folhetos, manuscritos e documentos eletrônicos (BELLOTTO, 2000).

Nos museus também se formam coleções, pois os objetos e documentos que estão salvaguardados nas instituições museais são resultado de uma seleção; são adquiridos conforme as características do museu, de acordo com sua missão e suas diretrizes de aquisições de acervos.

Segundo o Estatuto Brasileiro de Museus, em seu artigo $1^{\circ}$,

Consideram-se museus [...] as instituições sem fins lucrativos que conservam, investigam, comunicam, interpretam e expõem, para fins de preservação, estudo, pesquisa, educação, contemplação e turismo, conjuntos e coleções de valor histórico, artístico, científico, técnico ou de qualquer outra natureza cultural, abertas ao público, a serviço da sociedade e de seu desenvolvimento. (BRASIL, 2009, p. 1) 
Os centros de documentação "recebem as características dos documentos que armazenam, reproduzem ou referenciam". Bellotto também compartilha da mesma linha de pensamento de Tessitore quando afirma que os centros de documentação adquirem as características do material que preservam (BELLOTTO, 2000, p. 10). Desta forma, podem apresentar características da Arquivologia, Biblioteconomia ou Museologia, a depender de seu acervo e da forma como ele esse é tratado, podendo um mesmo centro ter essas três áreas de conhecimento convivendo harmonicamente.

Um centro de documentação pode reunir acervos de Arquivologia, Museologia e Biblioteconomia, e adquirir as características do material que preservam (BELLOTTO, 2000, p. 10), pois esses espaços têm como uma de suas características o fato de abrangerem tipologias de acervo diversificadas referentes à mesma temática.

Sendo assim, uma característica dos centros de documentação é serem alinhados a uma temática principal e reunirem acervo relativo a essa temática, ou seja, se especializam em determinado assunto ou área de conhecimento. No caso do centro de documentação estudado neste artigo, o CEDOC-CEIHE - o mote central é a História da Educação.

O que se percebe através dos autores referenciados é que os centros de documentação são instituições que misturam variadas tipologias, tendo acervos de duas ou mais áreas de conhecimento - Biblioteconomia, Arquivologia ou Museologia -, já que um acervo classificado em uma única área de conhecimento a tipificaria como outro tipo de instituição que não um centro de documentação.

A importância de uma comunicação contínua entre as diversas áreas do conhecimento que lidam com objetos patrimoniais é tratada por Cabral (2012), que ressalta a questão da interdisciplinaridade, outro elemento caracterizador dos centros de documentação. Nestas instituições há espaço para profissionais de vários saberes e competências, pois, além de toda a equipe necessária para o tratamento do acervo, geralmente também há pessoas envolvidas com a própria temática do centro de documentação. Ressalta-se aqui que as demais instituições de memória - arquivos, museus e bibliotecas - também possuem essa característica da interdisciplinaridade, sendo uma característica em comum desses espaços e não uma peculiaridade dos centros de documentação. O que ressaltamos é que, devido às diversas tipologias de acervos 
presentes num centro de documentação, essa comunicação entre várias áreas e profissionais se torna relevante.

Centros de documentação possuem funções de guarda e preservação dos acervos que estão sob sua responsabilidade. Esses espaços, independentemente da temática a que se dedicam, são guardiões de determinada memória e se configuram como instituições de pesquisa. Isto significa que os espaços devem ser pautados por procedimentos técnicos e organizacionais a fim de que os pesquisadores interessados em consultar seu acervo possam facilmente recuperar a informação ou as fontes de pesquisa de que necessitam.

Talvez esse seja o ponto no qual dialogam mais profundamente essas quatro tipologias de instituições de memória: o fato de terem por finalidade a coleta, a salvaguarda e a comunicação de seus acervos.

Esse último elemento, a comunicação, vai ser diversificado e mais ou menos complexo a depender de cada instituição. As bibliotecas, por exemplo, comunicam através do empréstimo e uso de suas obras; os arquivos através da disponibilidade de seus fundos ou documentos para pesquisa; os museus comunicam majoritariamente através de suas exposições, mas também através de ações educativas, palestras, catálogos; e, por último, os centros de documentação comunicam a partir da tipologia do material que salvaguardam: tanto podem comunicar por meio da disponibilização para pesquisa de seu material arquivístico, como por meio de exposições, ações educativas ou palestras.

Dessa forma, entendemos esses quatro tipos de instituições de memória guardam semelhanças entre si, possuindo a corresponsabilidade de preservação e cuidado técnico com os acervos.

\section{CEDOC - CEIHE: um espaço dedicado à História da Educação}

Após essa breve discussão teórica sobre os quatro tipos de instituições de memória - arquivos, museus, bibliotecas e centros de documentação - analisadas nesse texto, será abordado o centro de documentação estudado. 
O Centro de Documentação, CEDOC, é uma subdivisão do CEIHE - Centro de Estudos e Investigações em História da Educação - vinculado à Faculdade de Educação da Universidade Federal de Pelotas, FaE/UFPel, através do Programa de Pós-Graduação em Educação. Além do CEDOC, o CEIHE sedia também um Centro de Pesquisa.

Sobre a criação do CEIHE:

sua concepção em grande parte esteve norteada pelos debates e abordagens desse campo, onde despontam temas como: história das instituições escolares, cultura escolar, cultura material escolar, impressos estudantis, manuais escolares, cartilhas, memórias de professores, etc. [...] temas como a cultura material escolar, a estrutura interna das escolas, seus programas e currículos, os manuais escolares, os agentes educacionais, estão nas nossas análises, assim como, os sistemas educacionais. (ARRIADA; TAMBARA; TEIXEIRA, 2012, p. 23)

Conforme ressaltado por Elomar Tambara, esses dois núcleos são complementares: a História da Educação é o fio condutor que une esses espaços, tanto o CEDOC quanto o Centro de Pesquisa se dedicam a ela (TAMBARA, 2005).

Alguns dos objetivos do Centro de Pesquisa são: fomentar a pesquisa historiográfica; desenvolver investigações individuais e coletivas sobre diversos temas no campo historiográfico educacional; proporcionar pesquisas e estudos comparados; produzir trabalhos científicos e divulgá-los em diferentes fóruns; manter sessões de estudo de caráter teórico-metodológico; promover debates e seminários específicos; dar suporte aos alunos durante a fase de preparação de monografias, artigos, dissertações e teses (ARRIADA; TAMBARA; TEIXEIRA, 2012).

Além dos objetivos ligados às pesquisas em História da Educação, desde o seu surgimento, o CEIHE tem se dedicado à guarda, à preservação e à disponibilização de acervo vinculado à temática principal que tem sido o ponto central das discussões e reflexões do grupo integrante do CEIHE (ARRIADA; TAMBARA; TEIXEIRA, 2012).

Retomando as discussões expostas anteriormente, lembramos que centros de documentação e museus têm diversos aspectos em comum: ambos lidam com acervos e, mais especificamente, com constituição e comunicação de acervos, ou seja, há uma 
preocupação partilhada com a guarda, a preservação, a investigação e a comunicação nesses espaços, mesmo que os objetos salvaguardados tenham especificidades e que cada um desses lugares possua responsabilidades e peculiaridades que marcam diferenças entre uma instituição e outra.

Bellotto também observa os pontos convergentes entre estes espaços de memória: "os centros de documentação, assim como os museus, arquivos e bibliotecas têm como principais objetivos: recolher, tratar, transferir e difundir informações" (BELLOTTO, 2006, p. 232).

Sobre a organização do CEDOC, uma das primeiras atividades foi separar os itens por tipologia, ou seja, ver o que seria considerado acervo biblioteconômico, o que faria parte do acervo museológico e o que iria compor o arquivo (TEIXEIRA, SICCA, VIEIRA, DUARTE, 2013).

No que se refere aos acervos museológico e biblioteconômico, estes foram adquiridos pelo centro por meio de doações advindas das campanhas e também de materiais comprados por professores que hoje fazem parte da equipe do CEDOC. O acervo arquivístico é composto por materiais que vieram de escolas que fecharam; a intenção é se ter um arquivo permanente com esse material. No que diz respeito à sistematização desses documentos e objetos, cada categoria é tratada segundo a área de conhecimento na qual está inserida. Conforme Bellotto, arquivos permanentes são também históricos (BELLOTTO, 2000, p. 157). Esses arquivos são constituídos depois que os documentos não são mais utilizados para a função para a qual foram criados, tendo assim um caráter histórico. Neste caso, os documentos que estão no CEDOC são de escolas que já fecharam e seus materiais documentais estão no centro.

Simultaneamente aos procedimentos técnicos iniciados pela equipe do centro com os objetos que já existiam no CEIHE, começou-se a pensar em fazer convênios com outras instituições que teriam interesse em doar acervos para o Centro de Documentação. Atualmente, pensa-se em parcerias com bibliotecas que possuam acervos ou coleções que não contemplem suas próprias demandas e objetivos e, por isso mesmo, possam ser doadas ao CEDOC. 
Se fez certa campanha, não de uma forma ostensiva demais [...], mas fizemos pelos menos algumas campanhas, um certo apelo para algumas instituições escolares e outras instituições como bibliotecas, para que no caso de descartes ou obras consideradas de menor importância, geralmente dentro disso estão os livros didáticos, chamassem alguém do CEDOC, algum responsável para a gente olhar e eventualmente salvaguardar esse material, com isso conseguimos muita documentação. (ARRIADA, 2014)

Outra forma de aquisição de acervo é o recebimento de materiais advindos de escolas que fecharam, como a Escola Santa Margarida e o Colégio Salles Goulart. As escolas doam ao Centro de Documentação planos de aula, listas de presença, cartilhas escolares, etc. Tais coleções vão ao encontro do que o centro propõe: um acervo relativo à História da Educação em Pelotas e região.

Nesse ponto é relevante mencionar que o Centro de Documentação recebe muitas doações, até mesmo porque há todo um incentivo e uma preocupação por parte da equipe envolvida em preservar esses itens pertinentes a sua temática e missão, que é guardar o acervo relativo à História da Educação em Pelotas e região Sul do Rio Grande do Sul.

O acervo do CEDOC também é formado por materiais de alguns professores da Faculdade de Educação da Universidade Federal de Pelotas, a saber, que estão no centro por regime de comodato.

Os acervos que estão no centro em regime de comodato são, em sua maioria, livros. De acordo com entrevistas realizadas com os responsáveis pelo Centro de Documentação, a situação de empréstimo dos materiais, em oposição a uma possível doação definitiva, se deve ao fato de o local possuir poucos funcionários efetivos.

Em entrevista, os professores responsáveis pelo CEDOC revelam que parte do acervo do mesmo vem de suas coleções privadas:

Fomos preservando nos acervos privados nossos, tanto o Elomar como eu temos uma grande paixão, sempre tivemos, em tudo que é congresso [...] vamos a sebos, coletando, comprando, adquirindo, procurando ver material dessa região aqui. Hoje nós estamos disponibilizando esses acervos de cunho privado para o CEDOC que passa a ser um espaço público. (ARRIADA, 2014 - grifo da autora) 
O CEDOC arrola em seu acervo uma hemeroteca com destaque para dois jornais produzidos na cidade de Pelotas: "O Rebate" e "O Libertador”; acervo étnico; coleção Pelotas, Almanach e álbum de Pelotas; Coleção Rio Grandense; coleção de legislação imperial; acervo de textos escolares; coleção Brasiliana, livros publicados pela Editora Nacional; acervo tridimensional ligado à materialidade da cultura escolar1.

O acervo do CEDOC também é formado por materiais de alguns professores da Faculdade de Educação da Universidade Federal de Pelotas. Nesse contexto, cabe refletirmos sobre a transformação de coleções que estão em âmbito privado e passam ao domínio público. Coleções que num dado momento foram adquiridas para fazer parte de uma "biblioteca" particular e, posteriormente, passam a ser coleções abertas ao público. Assim, entende-se que esse processo de tornar público algo que antes pertencia à esfera particular tem aspectos comunicativos relevantes de serem elencados, já que da intenção dos colecionadores de dar acesso a seus materiais bibliográficos se pode depreender um sentido de "consciência" da importância que estes materiais - especialmente livros possuem para a pesquisa e também para a área específica do Centro de Documentação.

Os procedimentos técnicos de catalogação e sistematização de acervo são atividades contínuas. Entretanto, a fase inicial de processamento técnico do acervo é a mais exaustiva, exigindo maior força de trabalho, além de toda a criação de um sistema de indexação, do planejamento do banco de dados e da organização do material dentro do espaço.

Como dito anteriormente, os centros de documentação são espaços que podem abranger acervos, objetos e documentos das três áreas: Museologia, Biblioteconomia e Arquivologia. A tabela a seguir mostra a divisão do acervo do CEDOC nas três áreas de conhecimento:

\footnotetext{
${ }^{1}$ Folder explicativo do CEDOC, 2013.
} 
Tabela 1 - Tabela demonstrativa do acervo do CEDOC.

\begin{tabular}{l|l} 
Objetos museológicos & $\begin{array}{l}\text { Objetos tridimensionais - lápis, classes, palmatórias, flâmulas, } \\
\text { lousas, pedras de ardósia, etc. }\end{array}$ \\
\hline Objetos arquivisticos & Coleção de jornais. \\
\hline Objetos biblioteconômicos & Livros \\
\hline
\end{tabular}

Fonte: Tabela elaborada pela autora, 2014.

O centro de documentação escolhido como objeto neste trabalho - CEDOC-CEIHE - contém objetos relativos a essas três áreas. Conforme pode ser visto na fotografia a seguir:

Figura 2 - Fotos do acervo do CEDOC; acervo museológico; acervo biblioteconômico e acervo arquivístico respectivamente.
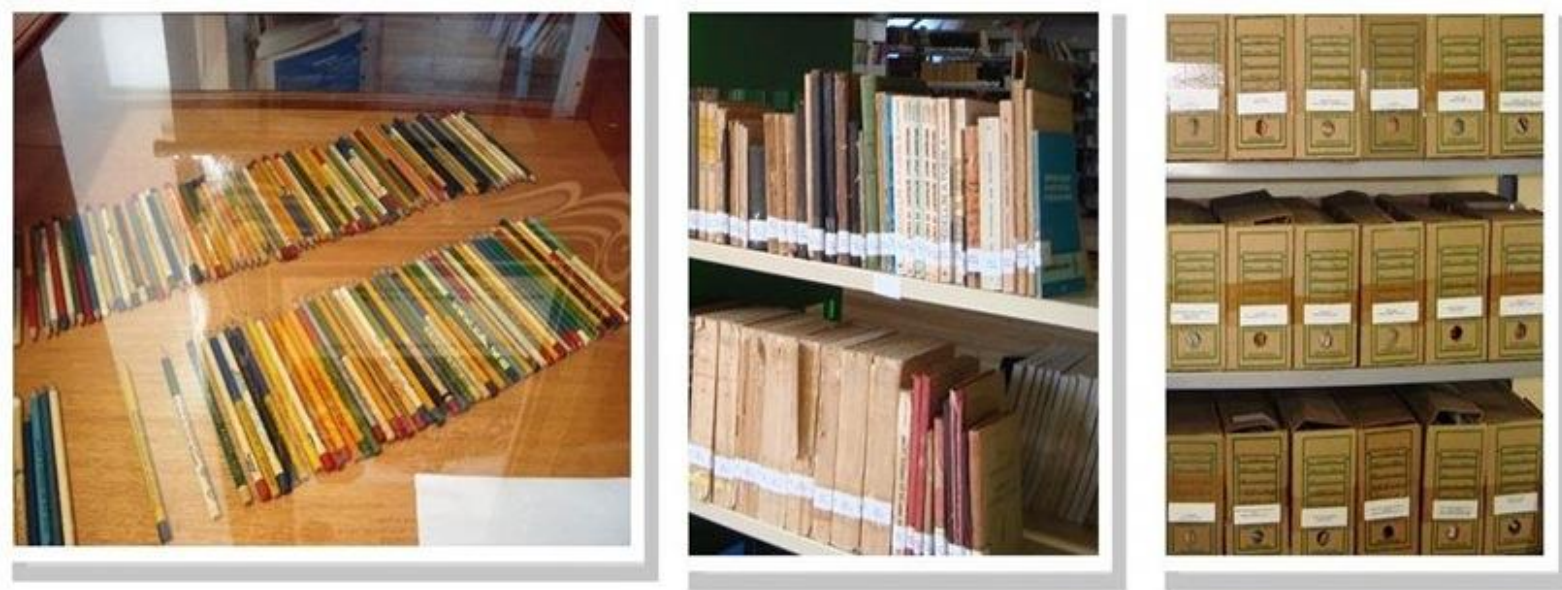

Fonte: foto da autora, 2014 .

O CEIHE e O CEDOC realizaram e realizam mostras expositivas, que podem ser consideradas “micro-exposições”, embora seja justo salientar que não há juízo de valor no emprego do termo, usado pela autora apenas para se referir a exposições temporárias que foram elaboradas no âmbito desses centros e que, aliadas a uma temática, divulgam o centro e seus acervos. 
A primeira mostra expositiva foi realizada bem próxima da criação do CEIHE, no ano de 2000, e tinha como tema "A História da Educação em Pelotas"; no ano seguinte, realizou-se uma mostra com as cartilhas escolares na educação pelotense; em 2003, outra mostra com os impressos da Faculdade de Educação e, em 2004, foram mostrados almanaques e álbuns na História da Educação pelotense.

A mostra expositiva mais recente realizou-se dentro da programação da $19^{a} \mathrm{ASPHE}$ (Associação Sul Rio Grandense de Pesquisadores em História da Educação)². Em parceria com o Hisales 3 e o Museu da Baronesa, a exposição intitulada "RECUERDOS: Registros da Cultura Material em Pelotas e Região" foi inaugurada na primeira quinzena do mês de novembro de 2013 e esteve disponível ao público de 7 de novembro de 2013 até 10 de fevereiro de 2014, período em que contabilizou 4.811 visitantes.

Essa exposição realizada durante o $19^{\circ}$ encontro da $\mathrm{ASPHE}^{4}$, bem como as demais elencadas, demonstram, a priori, dois elementos: o primeiro é uma preocupação por parte do CEDOC em comunicar através de seu acervo, pois, ao expô-lo ao olhar de um público sem ligação com a pesquisa na área da História da Educação, este toma conhecimento da existência e relevância do patrimônio salvaguardado pelo centro. 0 segundo elemento é inferido da expressiva visitação que a exposição recebeu: aproximadamente 4.800 visitantes em pouco mais de três meses. Tal cifra pode ser indicativa de que há, por parte do público visitante do Museu da Baronesa, interesse nessa temática e nesses materiais que além de estarem alinhados à História da Educação, se constituem em objetos e documentos utilizados nesse universo escolar e demonstram uma cultura escolar.

Essas exposições evidenciam igualmente uma intenção em comunicar através desses documentos e objetos alinhados à História da Educação, ou seja, o acervo é visto não só a partir de seu potencial de pesquisa, mas com potencialidades comunicativas.

\footnotetext{
${ }^{2} \mathrm{O}$ Encontro da ASPHE acontece anualmente e em cada ano se realiza em uma cidade diferente.

${ }^{3}$ HISALES - História da Alfabetização, Leitura, Escrita e dos Livros Escolares é, ao mesmo tempo, um grupo de pesquisa cadastrado no CNPq desde junho de 2006 e um projeto de investigação integrado desenvolvido na FaE/UFPel sob a coordenação da professora Dra. Eliane Peres. Site institucional disponível em: <http://wp.ufpel.edu.br/hisales/>. Acesso em 18 de maio de 2014.

${ }^{4}$ O encontro da ASPHE no ano de 2013 aconteceu na cidade de Pelotas/RS.
} 


\section{Considerações finais}

Este artigo teve como propósito discutir teoricamente acerca de quatro tipos de instituições de memória, a saber, arquivos, museus, bibliotecas e centros de documentação, buscando diferenciar os centros de documentação dos demais espaços. A seguir o estudo abordou a implantação do Centro de Documentação do Centro de Estudos e Investigações em História da Educação.

Os centros de documentação possuem como uma de suas especificidades o fato de trabalharem com uma temática, a saber, se especializarem e buscarem materiais específicos dessa área de interesse. O CEDOC-CEIHE, por exemplo, é um espaço destinado a guarda de acervos relacionados à História da Educação.

Arquivos, museus, centros de documentação e bibliotecas são similares por guardarem importantes parcelas do patrimônio, seja ele documental ou tridimensional, mas têm especificidades. Esses espaços, conforme observamos nesta pesquisa, se configuram como espaços híbridos onde dialogam variadas tipologias de acervos, mesclando materiais de duas ou mais áreas de conhecimento: Biblioteconomia, Arquivologia e Museologia.

Tendo em vista as definições encontradas para as quatro tipologias de instituições de memória, percebe-se que, no que se refere a arquivos e centros de documentação, as fronteiras são bastante tênues. Fica evidente, entretanto, que os centros de documentação em sua maioria estão alinhados a uma temática principal, ou seja, se especializam em determinado assunto ou área de conhecimento.

No CEDOC-CEIHE se percebem claramente essas características: há acervos das três tipologias - Museologia, Biblioteconomia e Arquivologia -, e todo esse material está alinhado a uma temática central que é a História da Educação. O CEDOC se enquadra na descrição de centros de documentação presente nesse trabalho.

Para pensar sobre centros de documentação, realizou-se uma pesquisa empírica explorando seu acervo e entrevistando os gestores da instituição. Essa etapa se mostrou de suma importância para o entendimento do funcionamento do CEDOC-CEIHE, bem como do surgimento do mesmo e de sua estruturação interna. As visitas regulares ao CEDOC, assim como as entrevistas e conversas com os profissionais que lá atuam, mostraram que esse local cumpre uma função importante enquanto centro de 
documentação, colocando à disposição para pesquisa uma variedade de documentos sobre a História da Educação em Pelotas e região sul do Rio Grande do Sul e salvaguardando essa memória. Paralelamente, há uma preocupação do CEDOC em comunicar seu acervo, pois desde o princípio do Centro de Estudos e Investigações em História da Educação já se realizavam mostras expositivas acerca de alguma temática pertinente ao mote principal do centro, a História da Educação. O CEDOC - Centro de Documentação do Centro de Estudos e Investigações em História da Educação - se configura como uma instituição de memória relevante para a temática.

O Centro de Documentação estudado neste trabalho apresenta as características de um centro de documentação, ou seja, não é uma biblioteca, nem um arquivo e nem um museu e, sim, um centro de documentação, o qual guarda documentos (no seu sentido geral) relevantes para a História da Educação: não apenas livros, jornais, cartilhas escolares ou objetos da cultura material escolar, mas sim documentos representativos para a História da Educação.

\section{Referências}

ARRIADA, Eduardo. [Entrevista]. Entrevista concedida a autora, no dia 10 de junho de 2014.

ARRIADA, Eduardo; TAMBARA, Elomar; TEIXEIRA, Vanessa Barrozo. Acervos escolares: espaço de salvaguarda e preservação do patrimônio histórico-educativo. Revista Didática Sistêmica, [da] Universidade Federal do Rio Grande, v. 14, n. 2, p. $15-29$ 2012, Disponível em: <http://www.seer.furg.br/redsis/issue/view/397>. Acesso em: 15 de outubro de 2013.

BELLOTTO, Heloísa Liberalli. Arquivos permanentes: tratamento documental. Rio de Janeiro: Editora FGV, 2006. 
BELLOTTO, Heloísa Liberalli. Patrimônio documental e ação educativa nos arquivos. Ciências e Letras: Revista da Faculdade Porto-Alegrense de Educação - RS, Porto Alegre, n. 27, p. 151-166, 2000.

BRASIL. Lei № 11.904, de 14 de janeiro de 2009: institui o estatuto de museus. Brasília, 2009. Disponível em: <http://www.planalto.gov.br/ccivil_03/_Ato2007-

2010/2009/Lei/L11904.htm>. Acesso em 13 de janeiro de 2014.

BRASIL. Lei $\mathbf{n}^{\circ}$ 8.159, de 8 de janeiro de 1991: dispõe sobre a política nacional de arquivos públicos e privados e dá outras providências.Brasília, 1991. Disponível em:

<http://www.planalto.gov.br/ccivil_03/leis/L8159.htm> acesso em 06 de abril de 2014

CABRAL, Rosimere Mendes. Arquivo como fonte de difusão cultural e educativa. Acervo: Revista do Arquivo Nacional. Rio de Janeiro, v. 25, n. 1, p. 35-44, 2012. Disponível em: <http://www2.an.gov.br/seer/index.php/info/issue/view/2> . Acesso em: 23 de novembro de 2013.

CHAGAS, Mário. Cultura, Patrimônio e Memória. Ciências e Letras: Revista da Faculdade Porto-Alegrense de Educação - RS, Porto Alegre, n. 31, p.15-29, 2002.

CHAGAS, Mário. Museália. Rio de Janeiro: JC editora, 1996.

FRATINI, Renata. Educação patrimonial em arquivos. Histórica: Revista Eletrônica do Arquivo Público do Estado de São Paulo, São Paulo, n. 34, 2009. Disponível em: <coralx.ufsm.br/tede/tde_busca/arquivo.php?codArquivo=4501>. Acesso em 29 mar. 2014.

GLOSSÁRIO ARQUIVÍSTICO. Arquivo Público do Estado de São Paulo. São Paulo, 2014. disponível em: <http://www.arquivoestado.sp.gov.br/permanente/glo_arq.php>. Aacessado em 06 de abril de 2014.

HORTA, Maria de Lourdes Parreira. Fundamentos da educação patrimonial. Ciências e Letras: Revista da Faculdade Porto-Alegrense de Educação - RS, Porto Alegre, n. 27, p. 2535, 2000.

NEVES, Rogério Xavier. As possibilidades educacionais dos centros de documentação e memória. 2005. 196 f. Dissertação (Mestrado em Educação) - Universidade Estadual de Campinas, Faculdade de Educação, Campinas, 2005. Disponível em: <http://www.bibliotecadigital.unicamp.br/document/?code=vtls000376585\&fd=y>. Acesso em: 04 de janeiro de 2014.

TAMBARA, Elomar. Centro de Estudos e Investigações em História da Educação - CEIHE. Revista Horizontes, v. 23, n. 2, p. 141-146, jul. / dez. 2005. Disponível em: <http://webp.usf.edu.br/edusf/publicacoes/RevistaHorizontes/Volume_02/uploadAddress/ _horiz-1[6577].pdf>. Acesso em 10 de janeiro de 2014.

TANUS, Gabrielle Francinne de S.C; RENAU Leonardo Vasconcelos; ARAÚJO Carlos Alberto Ávila. O conceito de documento em arquivologia, biblioteconomia e museologia. Revista Brasileira de Biblioteconomia e Documentação, São Paulo, v. 8, n. 2, p. 158-174, jul./dez. 2012. 
TEIXEIRA, Vanessa Barrozo; SICCA Aline; VIEIRA, Nitéri; DUARTE, Scheila. A organização e o tratamento técnico da hemeroteca do centro de documentação (CEDOC - CEIHE): um espaço para salvaguardar a História da Educação da cidade de Pelotas/RS. In: ENCONTRO DA ASSOCIAÇÃO SUL RIO GRANDENSE DE PESQUISADORES EM HISTÓRIA DA EDUCAÇÃO, 19, Pelotas (RS) e a 8 de nov. de 2013 . Anais eletrônicos... Pelotas: ASPHER/RS, 2013. Disponível em: <http://pt.scribd.com/doc/187000894/Caderno-deresumos-do-19\%C2\%BA-encontro-da-Asphe-RS>. Acesso em 29 de abril de 2014.

TESSITORE, Viviane. Como implantar centros de documentação. São Paulo: Arquivo do Estado, Imprensa Oficial, 2003, volume 9. (Projeto como fazer). 